(C) 1992 ISIJ

|IIIIIIIIIIIIIIIIII

論 文

IIIIIIIIIIIIIIIIIII

\title{
溶融還元炬への粉鉱石添加時の飛散抑制条件
}

\author{
片山 裕之* $*$ 桑原 正年 ${ }^{* 2} \cdot$ 大野 剛正 ${ }^{* 3}$ \\ 山内 雅夫 ${ }^{* 4}$. 平田 浩 ${ }^{* 5}$
}

\section{Decrease of Carry-over of Fine Ore Added into Smelting Reduction}

Furnace

Hiroyuki Katayama, Masatoshi Kuwahara, Takamasa OHno, Masao YamauchI and Hiroshi HiRATA

\section{Synopsis :}

In smelting reduction, it is desirable to use fine ore without agglomeration. In order to find the proper condition for fine ore addition to bath without injection, experiments involving a cold model and smelting reduction were performed.

(1) In the cold model test, a stream of fine materials (iron ore or coke) was passed into the gas of the counter flow. The rate of carry-over $(\mathrm{g} / \mathrm{s})$ depended on the surface area of the stream. The ratio of carry-over $(\%)$ decreased to less than $5 \%$ when the rate of supply was increased. Therefore, it is possible to decrease the ratio of carry-over during addition by decreasing the specific surface area of the stream, independent of the sort and size of fine materials.

(2) When fine ore was added through a hole in the shoulder of a $100 \mathrm{t}$ smelting reduction furnace, the ratio of carry-over was negligible when compared with the amount of dust originating from molten metal. So, it has been confirmed that top addition of fine ore without agglomeration is practical.

On the other hand, in the case of a fine carbonaceous material, the ratio of carry-over was high, even with an appropriate method of adding the fine ore.

Key words : smelting reduction; fine ore; top addition; carry-over.

\section{1. 緒}

鉄あるいはフェロアロイの溶融還元法開発の目的の一 つは，鉱石の塊成化工程（焼結法やペレット法）を省略 することである，近年，使用できる鈗石はほとんど粉状 になっていることから，上記の要求は，鉱石を粉のまま 使用できるようにすることを意味する．粉鉱石を直接利 用する方法としては，インジェクション法が知られてい るが，主原料である鉱石を溶融物に吹き込むことは配管 摩耗などの設備負荷が大きいこと，またとくに溶融金属 中に吹き込む場合には搬送のために多量のガスが吹き込 まれることに伴う副作用が問題となる1). したがって， 上方から投入してしかも飛散を許容限度内に抑制できる
方法が開発されることが望まれる。

すでに，著者らが行った $5 \mathrm{t}$ 規模のフェロクロム溶融 還元試験において，粉鉱石を上投入して飛散を $2 \%$ 以 下に抑制できる可能性が見出されている2). 本報では, 粉原料の飛散を抑制できる上投入条件を明らかにするた めに行ったコールドモデル試験，および，その上投入法 を大型炉にまでスケールアップしても使えるか，また， 微粉鉱石（鉄鉱石ペレットフィード）にも適用できるか などに着目して行った溶融還元炉試験の結果を報告す る

平成 2 年 4 月本会講演大会にて発表＼cjkstart平成 3 年 7 月 9 日受付（Received July 9, 1991）

* 新日本製鉄(株)プロセス技術研究所 工博 (Process Technology Research Laboratories, Nippon Steel Corp., 20-1 Shintomi Futtsu 299-12)

*2 新日本製鉄(株)プロセス技術研究所（現：浜田重工(株)) (Process Technology Research Laboratories, Now Hamada Heavy Industries)

*3＼cjkstart新日本製鉄(株)堺技術研究室（Sakai R \& D Lab., Nippon Steel Corp.)

*4 新日本製鉄(株)堺製鉄所（Sakai Works, Nippon Steel Corp.)

*5 新日本製鉄(株)プロセス技術研究所（Process Technology Research Laboratories, Nippon Steel Corp.) 


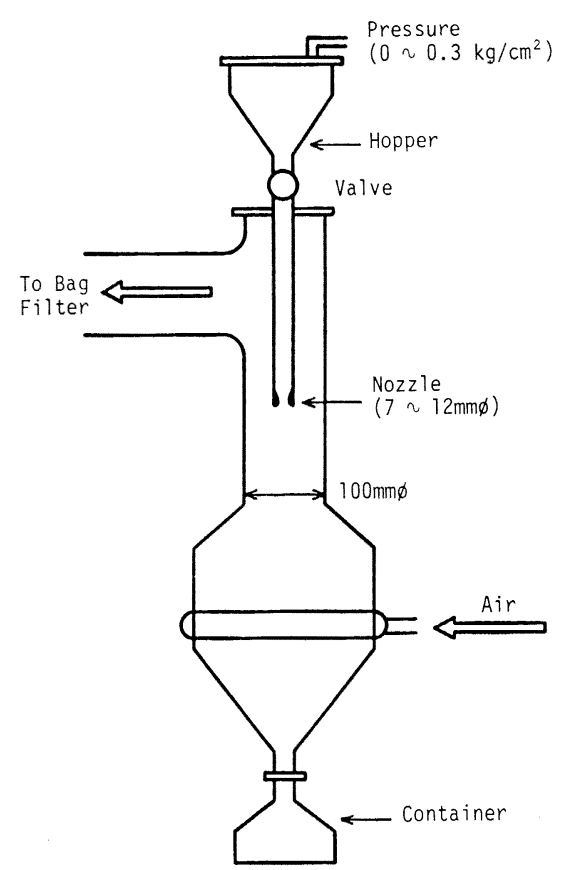

Fig. 1. Experimental apparatus.

Table 1. Conditions of experiments.

\begin{tabular}{c|c}
\hline Powder & $\begin{array}{l}\text { Iron ore A (Iron sand), Iron ore B (Pellet } \\
\text { feed), Coke powder }\end{array}$ \\
\hline Velocity of gas $(\boldsymbol{u})$ & $2.3,3.7,5.1(\mathrm{~m} / \mathrm{s})$ \\
\hline Diameter of nozzle & $7,10,12(\mathrm{~mm})$ \\
\hline
\end{tabular}

\section{2. コールドモデル試験}

\section{$2 \cdot 1$ 試験方法}

粉体流が上昇ガス流の中を落下する時の, 粉の飛散率 におよぼす諸要因の影響を，コールドモデルによって調 べた（Fig. 1)。容器胴部の周辺から 20 本の羽口を通し て Ar ガスを水汗方向に吹き込み，值管部に上昇ガス流 を作り，そこに粉体流を落下させ，飛散した粉の量を測 定した。粉体はホッパーから，バルブを通して供給量を 調整し，ノズルから落下させた。試験条件を Table 1 に示す．変更した要因は粉体の種類（粉鉱石 2 種類，粉 コークス), 粉体流の供給速度, 上昇ガス流速, および 粉体を落下させるノズルの径である。

各粉体の粒度構成を Fig. 2 に示す，各上昇ガス流速 に対して飛散の限界粒径（計算方法は $2 \cdot 3$ に示す）を 書き込んでいるが，個々の粒径については 50〜70\% が 飛散する川能性がある条件での試験である，特に鉱石

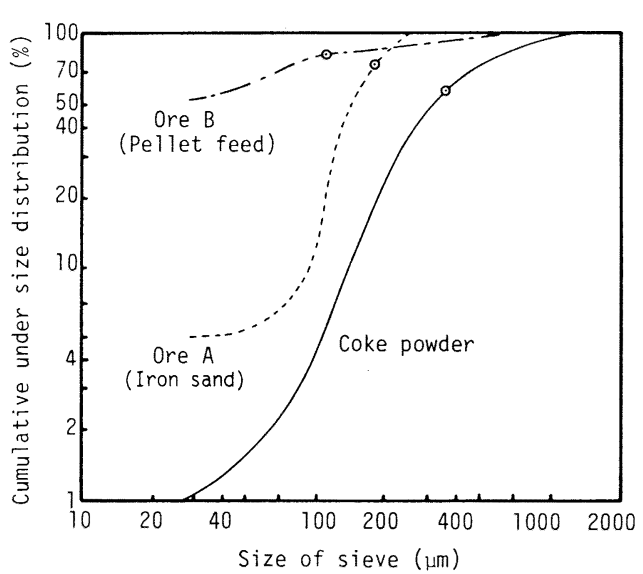

○: Calculated critical diameter for carry-over when the gas velocity is $2.3 \mathrm{~m} / \mathrm{s}$

Fig. 2. Size distribution of fine materials used for experiment.

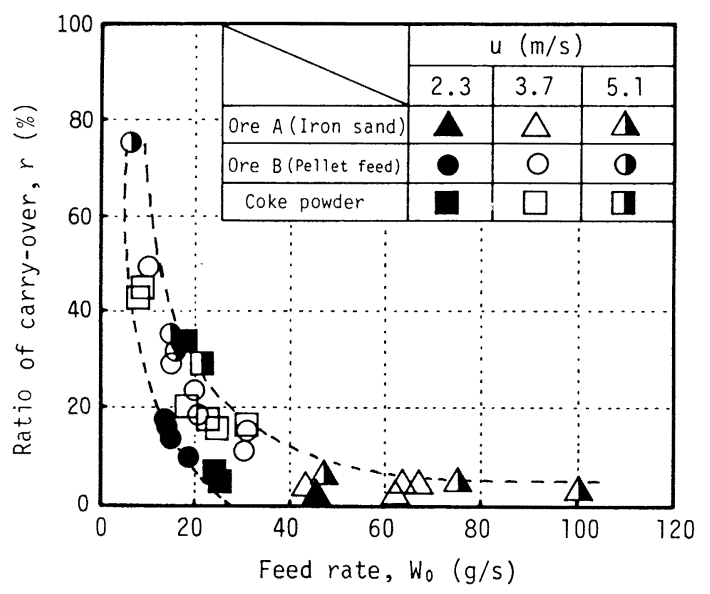

Fig. 3. Relation between ratio of carry-over and feed rate.

A（ペレットフィード）は粒径が小さい.

\section{$2 \cdot 2$ 試験結果}

飛散率 $(r)$ は粉体供給速度が増加すると急激に低下 する（Fig. 3)。一方，飛散速度（ $W_{c} ）$ は, Fig. 4 の鉱 石 $\mathrm{A}$ の場合に顕著に見られるように，供給速度がある 值以上では，ほぼ一定になる。これを，ノズル径との関 係で示すと（Fig. 5), 飛散率は反比例して減少するの に対して, 飛散速度はノズルにほぼ比例して増加してい る.

Photo. 1 は, 粉体流の状況を示す。粉体供給速度が 小さいと, $(b-1),(b-2)$ に示すように粉体流の状況が 時間的に変化し, 不安定で乱れが大きい. 一方, 供給速 


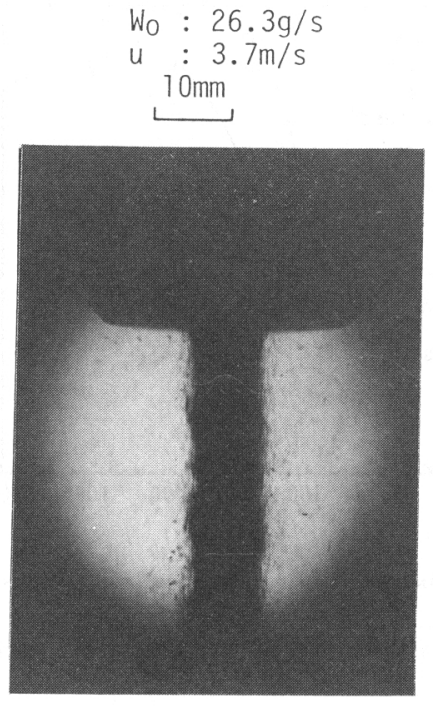

(a)

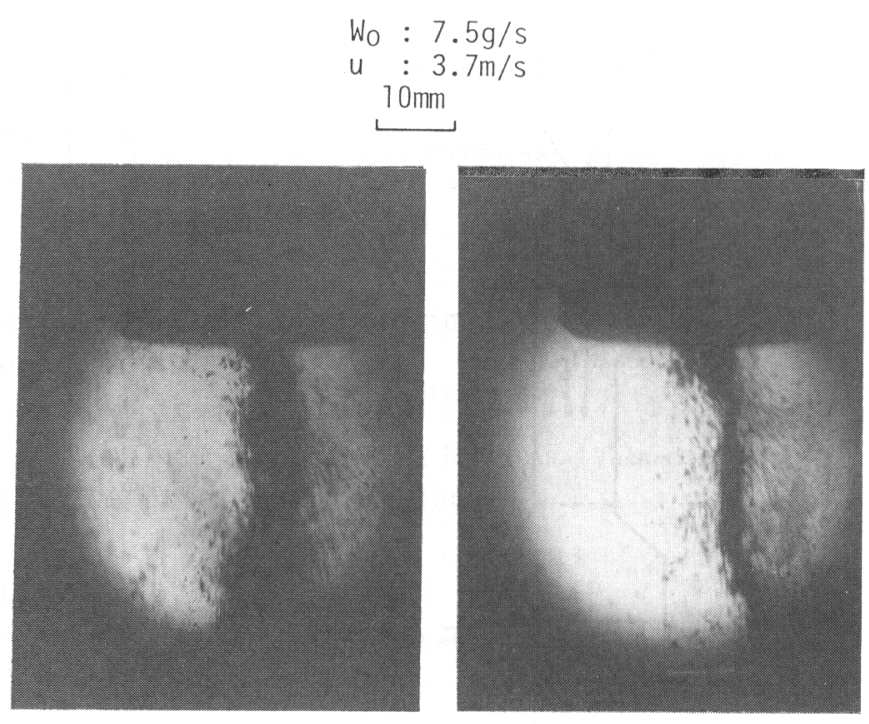

$(b-1)$

$(b-2)$

Photo. 1. State of stream of coke powder.

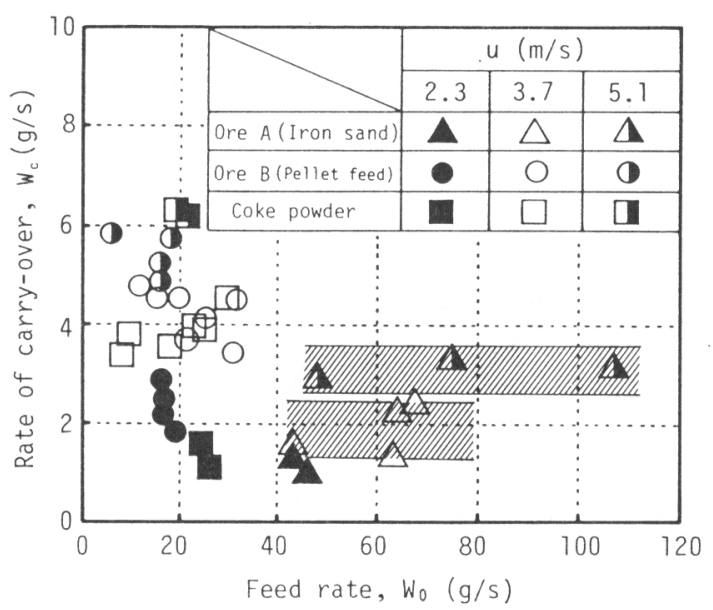

Fig. 4. Relation between rate of carry-over and feed rate.

度が大きくなると粉体流は安定化し，飛散は周辺部で観 察されるだけになる。

Fig. 6 は上昇ガス流速（u）の影響を示す。鈗石 B (ペレットフィード) の場合には, 飛散速度は上昇ガス 流速に正比例するが，それより粒径の大きい鉱石 $\mathrm{A}$ （砂鉄）およびコークス粉の場合には，上昇ガス流速の 3/2 乗に比例する. Fig. 6(a)の勾配と粉体の比重の関 係を Fig. 7 に示す。見かけ上，同一の上昇ガス流速に 捄ける飛散速度は, 粉体比重の $2 / 3$ 乗に逆比例してい

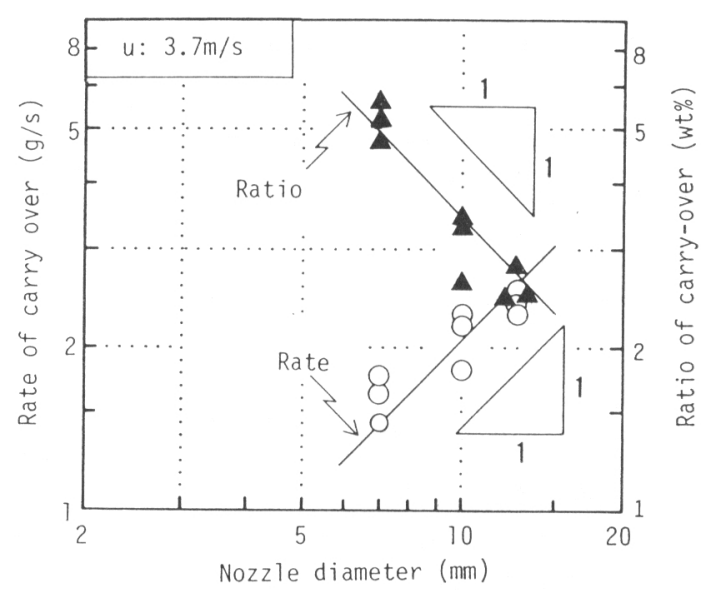

Fig. 5. Influence of nozzle diameter on carry-over (Iron sand).

\section{ることがわかる.}

以上のように，コールドモデル実験では，粉体の飛散 速度は，粉の比重が小さいほど，また，上昇がス流速が 大きいほど増加するという予想された傾向にあるもの の，供給速度を大きくすると，飛散率は急激に低下する こと,また, コークス粉の飛散量は粉鉱石の 2 倍程度で あることがわかった。

\section{$2 \cdot 3$ 考察}

上昇ガス流から個々の粉体に働く抗力 $(F)$ は $(1)$ 式 で表される. 


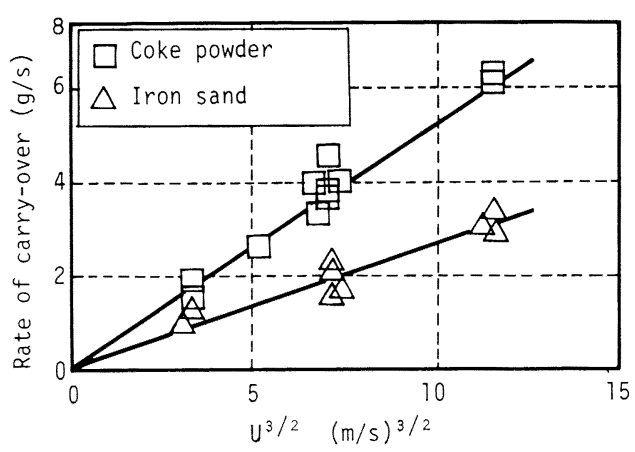

(a) Ore A (Iron sand) \& Coke powder

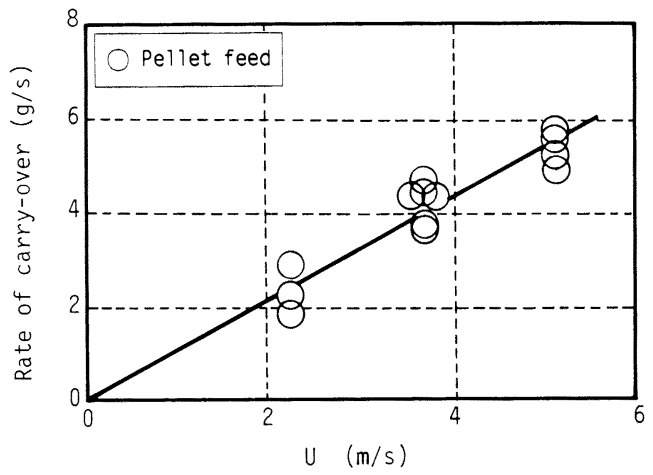

(b) Ore B (Pellet feed)

Fig. 6. Influence of gas velocity on carry-over.

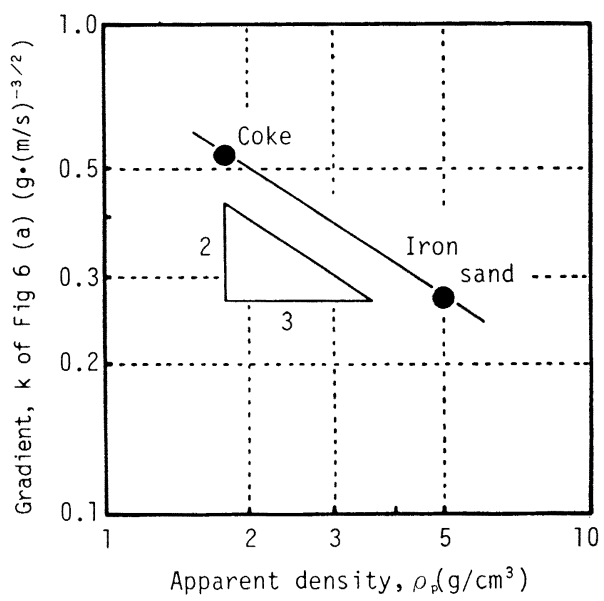

Fig. 7. Influence of apparent density of particle on carry-over.

$F=1 / 8 \cdot \pi \cdot C \cdot \rho_{g} u^{2} \cdot D p^{2}$

鈗石がペレットフィードのように微粒で, 粉粒のまわ りの $R e$ 数が 2 以下の場合, ( 1 )式中の $C$ は ( 2 )式で
表される.

$C=24 / R e$

これを(1)式に代入すると，Fは（3)式で表され る.

$F=3 \cdot \pi \cdot \mu \cdot D p \cdot u$

すなわち，この場合，粉体流に働く上昇ガス流速の影 響は 1 次に比例することになる.

一方, 粒子径が大きい, 鉱石 $\mathrm{B}$ や粉コークスの場合, 粉粒のまわりの $R e$ 数 $\left(R e_{p}\right)$ は2 500 の範囲にあり, $C$ は( 4 )式で表される.

$C=10 / \sqrt{R e}$

この場合には, ( 1 )式に代入して

$F=5 / 4 \cdot \pi \cdot \sqrt{\mu} \rho_{g}(D p \cdot u)^{3 / 2}$

となり，粉体流に働く上昇ガス流速の影響は $3 / 2$ 乗に 比例する.

以上のように, 飛散は粉体に働く上昇ガスの抗力 （F）に比例すると仮定すれば，Fig. 6 の関係を説明で きる。

上昇ガス流によって，粉が飛散するか否かは $F$ と (6)式に示される $W$ の大小関係を比較することによっ て決められる.

$W=1 / 6 \cdot \pi \cdot \rho_{p} \cdot g \cdot D p^{3}$

$F$ と $W$ の比較から飛散の限界粒子径; $D p_{c r i}$ を計算す ると(8)，(9)式のようになる.

$$
\begin{aligned}
& R e_{p}<2 \text { の場合 } \\
& D p_{c r i}=\left(18 \cdot \mu_{p} \cdot u / g\right)^{1 / 2} \ldots \ldots \ldots . . \\
& 2 \leqq R e_{p}<500 \text { の場合 } \\
& D p_{c r i}=\left(4 / 30 \cdot \sqrt{\mu} \rho / \rho_{p} \cdot g\right)^{3 / 2}
\end{aligned}
$$

（8)，（9)式により飛散限界粒子径を計算した結果を

Fig. 2 に書き込んでいる. 上昇ガス流速が $2.3 \mathrm{~m} / \mathrm{s}$ の 場合でも，60\% が飛散しうる条件であった，実際の飛 散率は Fig. 3 に示したように粉体供給速度が小さい場 合にはこれに近い值であるが，粉体供給速度が大きい場 合は $5 \%$ 以下であった.

したがって，粉体流では，実際に上昇ガス流にさらさ れる部分がどれだけかが飛散速度を決めることになる。

Fig. 5 で述べた結果は, 飛散速度は粉体流の表面積 に，飛散率は比表面積に比例していることを表してい る.

したがって，粉体流からの飛散は近似的に(10)式で表 される。

$$
\begin{aligned}
\text { 粉体飛散率 }= & \frac{(\text { 粉体流の表面積 })}{(\text { 粉体供給速度 })} \\
& \times(\text { 飛散限界粒子径以下の比率 })
\end{aligned}
$$


粉体が練かいほど, 比重が小さいほど, また上昇がス 流速が大きいほど飛散速度は増加するが, 粉体流比表面 積を小さくすることができれば飛散を抑制できることに なる。

粉体流に乱れがなければ, 粉体流の比表面積は粉体径 に逆比例する。したがって, 粉体流比表面積を小さくす るには, 粉体流の径が大きいこと（粉体供給速度が大き いこと), 粉体流の乱れが小さいこと（供給口の形状が 適正であること）拉よび粉体流が短いことが効果があ る. 今回は粉体流の長さの影響については試験をおこ なっていないが, 粉体流が長くなると表面積が長さに比 例して大きくなることに加えて，ノズルからの距離が大 きくなるにつれて粉体流の広がり, 乱れのために加速度 的に表面積がふえ, 飛散量が増加することが推定され る. 小林らはコールドモデル試験の結果として, 粉体流 がある長さになると上昇ガス流によって乱され吹き上げ られることを示している4).したがって飛散抑制のため には, 粉体流を極力乱さないことに加えて, 溶融物層ま での距離を極力小さくする工夫を併せて行うことが重要 である.

\section{3. 溶融還元炉の試験}

\section{$3 \cdot 1$ 試験条件}

大型溶融還元試験炉の設備および操業条件はさきに報 告されているものとほぼ同じであるが5), 今回の試験で は, Fig. 8 に示すように, 炉体上部傾斜部に設けた孔 より $\mathrm{N}_{2}$ ガスキャリアで粉原料を供給している点に特徵 がある. 吹込み口の角度 $(\theta)$ は 2 種類 $\left(20^{\circ}, 50^{\circ}\right)$, 吹 込み管の外径は 2 種類 $\left(50 \mathrm{~mm}, 80 \mathrm{~mm}\right.$;ただし, $\mathrm{N}_{2}$ 流 量, 固気比は一定とした）試験した。

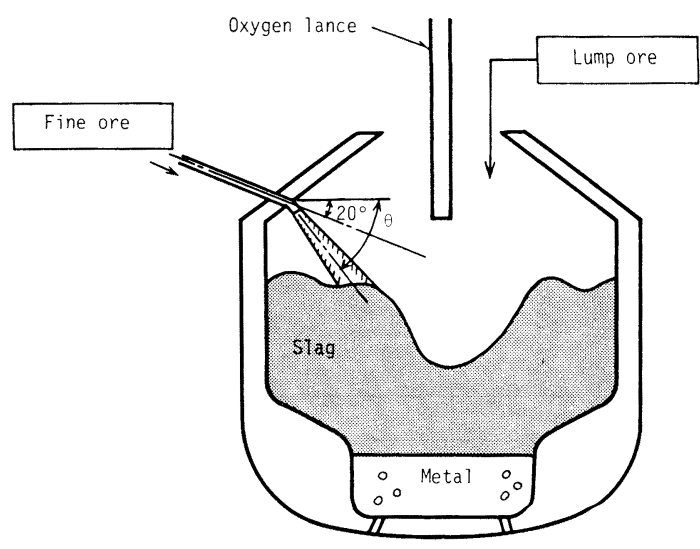

Fig. 8. Schematic drawing of material addition in smelting reduction furnace.
Table 2. Composition and size of added ore (wt \%).

\begin{tabular}{l|c|c|c|c|c|c}
\hline & $\begin{array}{c}\text { T. Fe } \\
(\%)\end{array}$ & $>5.0 \mathrm{~mm}$ & $5.0-2.0$ & $2.0-1.0$ & $1.0-0.5$ & $<0.25$ \\
\hline Lump ore & 68.0 & 98.0 & 2.0 & 0 & 0 & 0 \\
\hline Pellet feed & 68.0 & 0 & 8.0 & 8.8 & 4.9 & 83.3 \\
\hline Sinter feed & 68.0 & 0 & 22.5 & 21.7 & 17.0 & 38.8 \\
\hline
\end{tabular}

用いた鉱石の粒度条件を Table 2 に示す。粉釷石 (シンターフィードおよびペレットフィード) の個々の 粒については $90 \%$ 以上が飛散するような条件で溶融還 元炉は操業された。

鉄系ダスト発生量は集塵水をサンプリングして，その 中のダスト重量を成分分析值より求めた。鉄系ダストは 鉱石の飛散物とメ夕ルから発生したヒュームおよびバブ ルバーストダストの和である。 その分別定量は容易では ないので，本報では，塊鈗石を使用した場命のダスト中 鉄分量と, 粉鉱石を使用した場命のそれを比較して, 差 を鉱石飛散に起因するものと見なした，塊鉱石はその粒 度分布から見て, 直接飛散はほとんど無視できると思わ れるからである.

\section{$3 \cdot 2$ 試験結果}

粉鉱石として比較的粒度が大きいシンターフィードを 用いた場合の結果をFig. 9(a)に示す。縦軸は鉱石供給 量の中で全鉄飛散量（鉱不飛散のほかに，メ夕ルからの 発生ダストを含む）が占める割命を表す。この值は塊鉱 石の場合の範囲内にあること, かつ, 吹込み口の角度が 大きいほど小さくなっていること，また，吹込み管の径 すなわち流速の影響は小さいことがわかる6).

微粉鉱石（ペレットフィード）を用いた場合には (Fig. 9(b)), 吹込み口の角度が小さいと全鉄飛散量が 塊鉱石使用の場命より増えていることがあるが, 吹込み

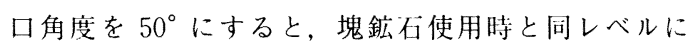
なっている6).

なお，スラグが増えると全鉄飛散量が滅少するのは, 主として酸素ジェットとメタルの接触によるメタル起因 のダスト量が減少するためであり7), 付加的に鉱石流が 短くなって鈗石飛散量が減少したことが効いていると思 われる.

以上のように, 粉鉱石の場令にも, 吹込み口の角度を 大きくして、スラグ層に突入するまでの粉鈗石流を短く すれば，大型炉でも鉱石飛散量は無視できる程度に抑制 できることが確認された。

一方, 粉鉱石と同じ条件で粉不岸 $(3 \mathrm{~mm}$ 以上; 7 $\mathrm{wt} \%, 3 \sim 1 \mathrm{~mm} ; 46 \mathrm{wt} \%, 1 \mathrm{~mm}$ 未満; $47 \mathrm{wt} \%)$ を添加 


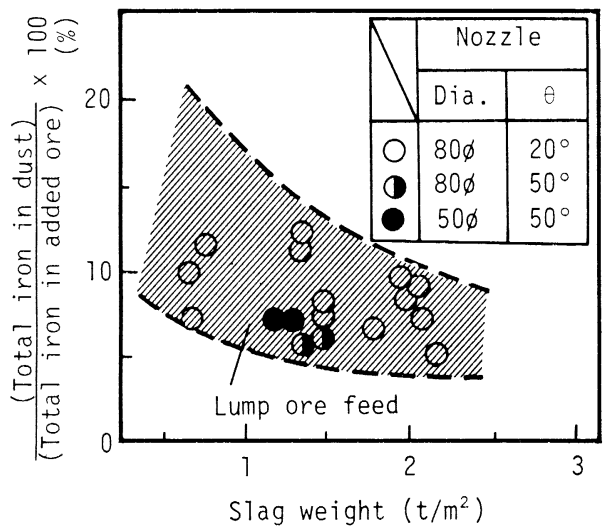

(a) Sinter feed ore

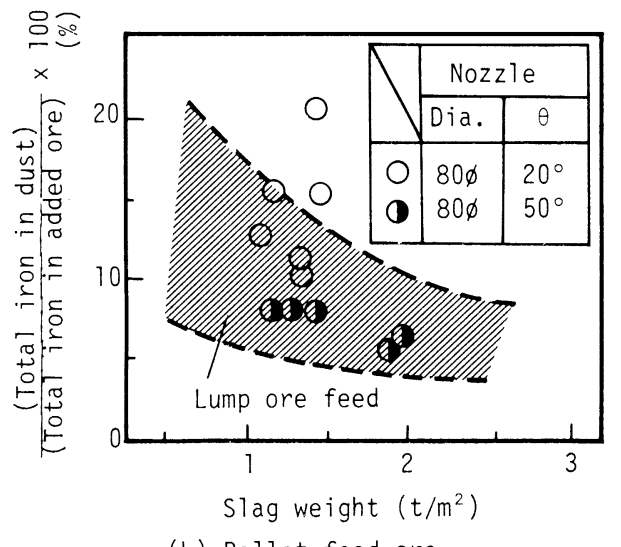

(b) Pellet feed ore

Fig. 9. Comparison of fine ore addition with lump ore addition.

した場合には，投入 Cのうちの $30 〜 47 \%$ がダストに 捕捉された ${ }^{9)}$.

\section{$3 \cdot 3$ 考察}

$3 \cdot 3 \cdot 1$ コールドモデル試験結果との関連

溶融還元炏試験では，粉鉱不については，飛散率を $2 \%$ 以下程度に抑えることができ，コールドモデル試験 結果から予想されたことを実証できた。一方，炭材の場 合には同じ添加方法では飛散率は約 1 桁大きい。このよ うに飛散率が粉鉱石と粉炭材で大きく異なることは, コールドモデル試験では見られなかった現象である。こ の差は，次のように説明できる，粉鉣不の場合は，空間 を移行していったんスラグ層に入るとスラグに濡れるた めに以後の飛散が起こりにくいのに対して，炭材の場合 にはスラグに濡れないので，炉内に存在している限りは 最後まで飛散の叮能性がつきまとう。すなわち，粉鉱石
と炭材の飛散率の差は，いったんスラグ層に達してから 以後の飛散の差を反映しているものと考えられる.

$3 \cdot 3 \cdot 2$ 実用プロセスとしての粉原料の使用法

粉鉱石を直接あるいは予備還元後，粉のまま上方か ら，飛散を無視できる程度に抑制しつつ添加できること が大型炉でも実証された。これは，溶融還元法の目的の 一つである塊成化工程の省略が問題なく行えること示す とともに，スラグによって酸素ジェットとメタルを遮断 して行う多量スラグ型操業が粉鉣石の場合にも可能であ ることを示すものとして意義がある.

それを可能にする必要条件は投入口を極力スラグに近 付けて粉鉱石流の比表面積を小さくすることである．今 回は，炉体側壁から添加する方法が使えることを示した が，その他にも，上方から简を差し込むこと，必要に よっては流速を大きくすることなど8)種々の方法が考え られる．その中で，今回の方法は，流速を大きくしなく ても飛散が抑制でき，搬送管の摩耗が少ないことなどが 長所として挙げられる。

一方，粉炭材については，粉鉱石と同じ方法では飛散 を抑制できない.したがって，別のアプローチが必要で ある ${ }^{9)}$.

\section{4. ま と め}

粉鉣石を上投入しても飛散を抑制できる条件を見いだ すために，コールドモデル実験と大型転炉を用いた溶融 還元試験を行い，次の諸点を明らかにした。

（1）上昇ガス流の中に粉体流を落下させた時の粉体飛 散量は，粉体流の表面積に比例する，粉体流の比表面積 を小さくすることによって, 粉体粒度, 比重, 上昇ガス 流速によらずに飛散を飛散率を抑制することが叮能であ る。

(2)溶融還元大型試験で，粉鉱石流を短くするよう に，炉壁に設けた孔からスラグが多い状態の炉内に流し 込む方式で，微粉鉱石についても飛散を無視できてる程 度に抑制できることを確認した。したがって，粉鉱石添 加に関しては塊成化は省略可能である。しかし，同じ方 法で粉炭材を添加した場合には，飛散率は $30 \%$ 以上と 高かった。

なお，本論文中「3，溶融還元炉の試験」は日本鉄鋼 連盟溶融還元研究開発委員会の共同研究に打いて得られ たものである。

\section{記 号}

$r:$ 飛散率一添加した粉原料のうち飛散した割合（\%) $W_{c}$ : 飛散速度一単位時間の飛散量 $(\mathrm{g} / \mathrm{s})$ 
$W_{o}$ : 粉体供給速度 $(\mathrm{g} / \mathrm{s})$

$F:$ 上昇ガス流から粉体に働く抗力

$C:$ 抵抗係数

$\rho_{g}:$ ガス密度 $\left(\mathrm{g} / \mathrm{cm}^{3}\right)$

$u:$ 上昇ガス速度 $(\mathrm{m} / \mathrm{s})$

$D p:$ 粉体粒子径

$R e_{p}:$ 粒の回りのレイノルズ数

$\mu:$ ガスの粘性係数 $(\mathrm{g} / \mathrm{cm} \cdot \mathrm{s})$

$\rho_{p}:$ 粉の比重 $\left(\mathrm{g} / \mathrm{cm}^{3}\right)$

$g:$ 重力の加速度

$D p_{c r i}:$ 飛散の限界粒子径

\section{文献}

1 ) 山内雅大, 茨城哲治, 金本通降, 片山裕之, 大野剛正: 材料とプロセス，4(1991),p. 1172
2) 片山裕之, 桑原正年, 平田浩, 八木次郎, 斎藤力, 藤田正樹: 鉄と鋼, 76 (1990), p. 1885

3 ) 森 芳郎, 古田文武: 詳論化学: I学単位操作 I (1962), p. 223 [朝倉書店]

4 ) 小林三郎, 徳田晶則: 鉄と鋼, 73 (1987), S750

5 ) 山内雅大, 茨城哲治, 金本通隆, 松毛充高, 平田浩, 稲谷捻宏: 材料とプロセス, 4 (1990), p. 1074

6 ) 山内雅夫, 茨城哲治, 金本通隆, 片山裕之, 大野剛正, 緒方征司: 材料とプロセス, 4 (1991), p. 1171

7 ) 大野剛正, 山内雅大, 茨城哲治, 金本通隆, 片山裕之, 緒方征司: 材料とプロセス, 4 (1991), p. 1170

8 ）室屋正廣, 菊地一郎, 松原真二, 川上正弘, 高橋謙治, 長谷川輝之: 材料とプロセス, 4 (1991),p. 1168

9 ) 片山裕之, 桑原正年, 小林勝明, 茨城哲治, 金本通隆: 材料とプロセス， 4 (1991), p. 36 